\title{
Memória e anti-memória \\ no projeto de Peter Eisenman e Jaquelin Robertson para o Bloco 5 de Koch-/Friedrich- straße, Berlim
}

\author{
Carolina Ferreira de Carvalho, \\ Jorge David Morales*
}

\begin{abstract}
Resumo Este artigo visa explorar a importância da memória e da anti-memória no projeto vencedor do concurso para o Bloco 5 de Koch-/Friedrichstraße, do escritório Eisenman/Robertson Architects, defendendo que o método utilizado pelos arquitetos se dá por uma "psicanálise da cidade". Para tanto, são abordados os conceitos de história, memória e anti-memória aplicados ao contexto da reconstrução de Berlim pós-Guerra; tendo como base textos das áreas de história, sociologia, filosofia e psicanálise, além de textos dos próprios arquitetos, bem como de seus estudiosos e críticos. Nesse sentido, o artigo tem por objetivo expor a forte carga mnemônica explorada no referido projeto e a maneira crítica com que os arquitetos abordam o tema da memória, tão explorado à época de sua elaboração.
\end{abstract}

Palavras-chave: memória, anti-memória, Peter Eisenman, Jaquelin Robertson.

\section{Memoria y anti-memoria en el proyecto de Peter Eisenman y Jaquelin Robertson para el Blo- que 5 de Koch-/Friedrichstraße, Berlín}

\begin{abstract}
Resumen Este artículo explora la importancia de la memoria y la anti-memoria para el proyecto vencedor del concurso para el Bloque 5 de Koch-/Friedrichstraße, de Eisenman/Robertson Architects, defendiendo que el método utilizado por los arquitectos se da por una "psicoanálisis de la ciudad". Son abordados los conceptos de historia, memoria y anti-memoria aplicados al contexto de la reconstrucción de Berlín pos-Guerra. El estudio cuenta con textos de las áreas de historia, sociología, filosofía y psicoanálisis, además de textos de los proprios arquitectos, de estudiosos y de críticos del proyecto. Así, el objetivo es exponer la fuerte carga mnemónica explorada en el proyecto referido y la manera crítica con que los arquitectos abordan el tema de la memoria, tan explorado por entonces.
\end{abstract}

Palabras clave: memoria, anti-memoria, Peter Eisenman, Jaquelin Robertson.

\section{Memory and anti-memory in Peter Eisenman and Jaquelin Robertson's project for Koch-/Friedrichstraße Block 5, Berlin}

\begin{abstract}
This paper aims to explore the importance of memory and anti-memory in the contest for Block 5 by Koch/ Friedrichstraße's winning project, by Eisenman/Robertson Architects, defending here that it takes place through a "psychoanalysis of the city". Therefore, the study broaches the concepts of history, memory and anti-memory applied to context of post-War Berlin reconstruction. The study was based on texts from history, sociology, philosophy and psychoanalysis, in addition to the writings of the architects themselves and to those of their scholars and critics. Thus, the paper aims to expose the strong mnemonic load explored in the mentioned project and the critical way used by architects about the subject of memory, so explored at the time.
\end{abstract}

Keywords: memory, anti-memory, Peter Eisenman, Jaquelin Robertson. 
projeto ora abordado localiza-se temporalmente no início da década de 1980 - no período chamado de pós-moderno. Tal momento se inicia nos anos 1960 e se estende até o fim dos anos 1980 e tem como características principais a revisão e a crítica aos preceitos modernos. Josep Maria Montaner (2007) aponta que um desses movimentos de revisão pode ser identificado através da reintrodução das preexistências ambientais à cultura arquitetônica, sendo elas constituídas por conceitos como tradição, história e monumento, o que vai de encontro à doutrina da tábula rasa pregada pela Carta de Atenas.

Tal movimentação é uma pauta presente primordialmente no núcleo italiano de revisores e críticos, do qual Montaner (2007) destaca as figuras de Ernesto Nathan Rogers, Ludovico Quarani, Giulio Carlo Argan, Manfredo Tafuri e Aldo Rossi. Todos eles, de alguma maneira, tratavam a arquitetura e a cidade como sendo componentes indissociáveis e interdependentes. Em seus primeiros estudos críticos, entre os anos de 1967 a 1975, Peter Eisenman não se posiciona nesta discussão acerca do retorno às tradições e memórias da cidade, tema que só virá à tona em seus trabalhos no final da década de 1970.

Segundo K. Michael Hays (2010), é apenas a partir de 1978 que o sítio passa a ser fator de maior importância na significação prática para os trabalhos de Eisenman, data que inaugura o que pode ser classificada como uma segunda fase de suas elaborações críticas e projetuais. E, somente em 1983, o termo "memória" é mais profundamente explorado e problematizado em seus escritos: tanto na introdução para a primeira edição americana de $A$ arquitetura da cidade, de Rossi, quanto no ensaio para o número 53 da revista Architectural Design, texto no qual Eisenman e seu sócio Jaquelin Robertson expõem os conceitos e diretrizes da proposta ganhadora do concurso para o Bloco 5 de Koch-/Friedrichstraße, em Berlim.

O edifício, localizado na interseção de Friedrichstraße com o Muro de Berlim, pertence a esse segundo momento da obra do arquiteto, em que as relações internas da arquitetura deixam de ser seu único foco de análise. Ao contrário, as "cidades de escavação artificial" (nome que engloba a série de projetos com essas mesmas características) são constituídas de explorações projetuais que, pela primeira vez, transportam a atenção de Eisenman para a cidade objetiva e seus elementos formadores: o sítio, a história, a memória e

* Carolina Ferreira de Carvalho é Arquiteta e Urbanista, Mestranda em Arquitetura pelo Programa de Pós-graduação em Arquitetura da Universidade Federal do Rio de Janeiro (PROARQ/UFRJ), ORCID <https://orcid.org/00000003-0059-3611>. Jorge David Morales é Arquiteto e Urbanista, Mestrando no programa de pós-graduação em arquitetura PROARQ da Universidade Federal do Rio de Janeiro - UFRJ, ORCID $<$ https://orcid.org/0000-00033195-2525>. também o que Eisenman e Robertson chamarão, posteriormente, de "anti-memória" (EISENMAN; ROBERTSON, 1983, p. 92, tradução nossa).

Dessa forma, a fim de melhor explorar o uso que os arquitetos fazem dos conceitos de memória e anti-memória em seu projeto, este artigo procura discutir o que se entende por memória e sua diferença do que se compreende por história, distinção importante no discurso dos arquitetos em questão. Para essa discussão, tais conceitos foram pautados, principalmente, pelas formulações dos historiadores Pierre Nora e Jacques Le Goff, e autores como Michel Foucault, Michael Pollak e Andreas Huyssen, além de discussões recentes sobre o tema. 
Posteriormente, o artigo expõe características gerais de projetos que podem ser enquadrados como um segundo momento de Peter Eisenman, as "cidades de escavação artificial", e procura explanar o por que de se acreditar que seus mecanismos de atuação aproximam-se da psicanálise freudiana, tendo como base argumentos do próprio Sigmund Freud e de Jacques Derrida. Daí o projeto escolhido para expor a manifestação de tais resoluções em arquitetura ser o de Berlim (o Bloco 5 de Koch-/Friedrichstraße), pois nele estão realçadas particularidades provenientes da segmentação dessa cidade no pós-Guerra. Faz-se importante levantar, também, as questões motivadoras do evento promotor do concurso que levou à vitória a proposta de Eisenman e Robertson, pois são de grande impacto no produto gerado. Após sua contextualização, será possível debater o conceito de anti-memória, específico do projeto em questão.

Cabe salientar que conceitos e expressões originárias da psicanálise e da filosofia foram consultados para uma melhor compreensão do projeto analisado. Isso se deve também ao fato de esses campos do saber possibilitarem a comparação da arquitetura de Eisenman e Robertson a uma espécie de "aparelho psíquico" da cidade de Berlim - seus arquivos recalcados e trazidos à tona pelo projeto da dupla. Assim, pretende-se estabelecer uma ligação entre a carga mnemônica de Berlim, acessada pelo que se chama aqui de "psicanálise da cidade", e o projeto para o Bloco 5 de Koch-/Friedrichstraße, cujo arquiteto muitas vezes é conhecido por seus trabalhos indiferentes às questões das cidades.

\section{História e Memória - uma distinção}

\section{História}

No projeto de Peter Eisenman e Jaquelin Robertson, a distinção entre história e memória é fundamental, bem como ressalta Pierre Nora (1984) em sua obra Les lieux de mémoire, na qual, já no primeiro capítulo, aponta as diferenças entre ambos conceitos que operam sobre as mesmas matérias: o passado e o presente. Para o autor, história seria a reconstrução do que já passou; em suas palavras, "[... ] a reconstrução sempre problemática e incompleta do que já não é [...] uma representação do passado." (NORA, 1984, p. 21, tradução nossa). Ainda no mesmo capítulo, Nora (1984) chama atenção para o fato de que a história e a memória estiveram por muito tempo atreladas uma à outra.

Jacques Le Goff (1988), em História e memória, é outro autor que reforça essa ligação quando expõe as origens da disciplina da história, que teria surgido como um relato, "[...] a narração daquele que pode dizer 'eu vi, senti'." (LE GOFF, 1988, p. 9), partindo da história-relato, história-testemunho. Mas, com o advento da historiografia, a história foi se tornando uma operação intelectual (NORA, 1984, p. 21) e o caráter subjetivo da memória fez com que fosse afastada do que antes era uma união. Isto é, ela comprometeria a objetividade científica da qual a história foi dotada - ciência essa que levou Marc Bloch a considerar a história como "[...] a ciência dos homens no tempo [...]" (BLOCH apud LE GOFF, 1988, p. 17-18).

Ambos livros citados estão situados em um período de revisão historiográfica, em que não só há a retomada da importância dada ao passado - o que Andreas Huyssen (2000) aponta como parte do deslocamento do foco que era dado ao futuro nas primeiras 
décadas do século XX e que passa a ser direcionado ao passado, principalmente a partir da década de 1980 -, como também surgem os questionamentos sobre os pontos de vista que ditam a escrita da história, sinalizados por Le Goff como "a tomada de consciência da construção do fato histórico, da não-inocência do documento [...]" (LE GOFF, 1988, p. 11). Com essa passagem, o historiador reforça uma questão já colocada por Michel Foucault nos anos 1960, através de seu livro Arqueologia do saber.

Na referida obra, Foucault (1969) questiona a concepção linear e teleológica da história, além de, é claro, a maneira como a disciplina opera e decifra sua fonte primordial, o documento. Sendo assim, o filósofo defende que a história, tradicionalmente, tinha o papel de guardar os monumentos do passado e transformá-los em documentos, para daí decodificar suas informações que, segundo ele, raramente são verbais (FOUCAULT, 1969). O papel da história, então, era apenas de arquivo.

Vale ressaltar que este arquivo é registrado a partir de um determinado ponto de vista, aquele que se encontrava no poder ao ponto de ter a autoridade de determinar o que seria arquivado e o que seria omitido (SCHWARTZ; COOK, 2004). Já a nova disposição da história, de acordo com Foucault (1969), seria a de transformar os documentos em monumentos, decifrando o que se encontra em sua profundidade, uma espécie de arqueologia "[...] para a descrição intrínseca do monumento." (FOUCAULT, 1969, p. 8), o que exporia a multiplicidade de estratos nele presentes.

Pode-se afirmar, portanto, que a história, por tradição, é tomada como a portadora do saber instituído, daquele que se reconhece como o passado oficial e dotado de uma objetividade científica. O reconhecimento das diversas camadas intrínsecas no documento - e, com isso, na história, incorporando diversos outros discursos e reconhecendo que eles "[...] não t[ê]m apenas um sentido ou uma verdade [...]" (FOUCAULT, 1969, p. 144) - é de suma importância para a atuação de Eisenman em suas "escavações artificiais". Como o nome já diz, as escavações do arquiteto realizam a expedição "arqueológica" (para usar o termo de Foucault) nos arquivos mnemônicos da cidade.

\section{Memória}

Como já abordado, após a Segunda Guerra, a memória passou a ser aplicada às discussões sobre arquitetura e cidade. Andreas Huyssen (2000) argumenta que tal interesse teria se intensificado a partir da década de 1980, quando passa a existir um olhar preponderante para o passado-presente, não mais voltado para o futuro.

Pode-se dizer que a memória é a capacidade por meio da qual o passado é retido e lembrado. Essa faculdade teria como locus a pisque humana, que conduz, portanto, a um plano subjetivo. Jacques Le Goff (1988) a define, em primeira instância, como uma função psíquica de atualização de informações passadas ou que o ser humano considera passadas, fazendo uma distinção mais ampla entre os tipos de memória que ocorreram ao longo da história.

A memória é uma entidade primária nas cidades e na sociedade como tal. Sua relevância é denotada precisamente quando é diferenciada da história. Costuma atuar como elemento que contribui para a história e pode manter-se vinculada a ela. Porém, isso 
não modifica seu caráter autônomo. Para Le Goff (1988), a capacidade da memória de se colocar fora do tempo a separa de maneira radical da história. E, assim, de acordo com a orientação que assume, pode distanciar-se ou juntar-se a ela.

A memória, independente da história, permite a visualização de outros fatos: não pode ser calada e muitas vezes opõe-se ou contrapõe-se à história oficial. Michael Pollak (1989) refere-se a essa questão quando relaciona esquecimento, memória e silêncio. Por meio das histórias contadas por sobreviventes da Segunda Guerra Mundial, o autor mostra que as lembranças e as narrativas baseadas na memória não estão necessariamente refletidas na história oficial.

Memórias que podem ser carregadas de dor ou vergonha tendem a criar uma história com vazios e silêncios que não mostram o quadro completo que a memória reflete em cada indivíduo e, portanto, na sociedade. Essas memórias são transmitidas entre gerações, em redes sociais, políticas ou associativas, que ele chama de maneira "subterrânea" (POLLAK, 1989, p. 4). O autor aponta que tal memória não oficial se opõe à memória organizada, uma vez que essa última se resume à imagem elaborada pela maioria da população ou à imposta pelo Estado. É devido a essa oposição e a essa maneira de transmissão que a memória não oficial teria maior dificuldade de manter-se intacta ao longo do tempo, e poderia apresentar variações até o dia em que possa vir a invadir o espaço público e a manifestar-se.

Equiparável à história, a memória também representa a luta pelo poder, pelo que deve ser lembrado ou esquecido, pelo que se constrói em seu nome, o que se cala e o que se mostra na esfera pública. Conforme definido por Pierre Nora (1984), está em evolução permanente, sujeita a mudanças entre recordação e amnésia, entre latências e revitalizações, pois é a própria vida encarnada por grupos vivos.

\section{"Cidades de escavação artificial"}

"Cidades de escavação artificial" foi o nome dado à série que reunia projetos do que pode ser classificado como um segundo momento de Peter Eisenman (1978-1988), que mostra uma atenção e uma sensibilidade muito maiores às questões da cidade objetiva. A mudança na sua abordagem projetual foi tanta que Ignasi de Solà-Morales (1995) escreveu um ensaio para a revista espanhola AV Monografías quando da edição temática sobre Peter Eisenman, no qual categoriza seu trabalho até os anos 1990 em três diferentes fases: forma, memória e acontecimento.

Evidentemente, a fase aqui em questão é a referente à memória, nas palavras de Solà-Morales, pelo fato desses projetos voltarem-se para o lugar, para a arqueologia (no sentido foucaultiano). Muito embora o arquiteto catalão afaste a possibilidade dessas "escavações" serem enquadradas no que se pode chamar de contextualismo (SOLÀ-MORALES, 1995, p. 22), pois, mesmo que haja uma interação dos projetos com seu exterior, as reflexões sempre partem do interior da arquitetura; além de os elementos da cidade com os quais Eisenman dialoga serem, em sua maioria, peças já ausentes do tecido urbano, que já não estão mais presentes fisicamente (ou, ao menos, acessíveis superficialmente) no espaço.

Phyllis Lambert (1994), diretora do Canadian Center for Architecture, instituição canadense que abrigou a exposição "Cities of artificial excavation" em 1994, afirma 
que o ponto de partida desses projetos é a abstração e o remonte das particularidades do sítio. Isto é, a apropriação de componentes atuantes da formação histórica desses locais para a criação dos projetos como "narrativas", provenientes de uma "ficção" criada pelo arquiteto.

O conceito de ficção parte das investigações de Eisenman entre as décadas de 1970 e 1980, nas quais tenta romper com o pensamento que chama de "clássico", algo que acredita ter se prolongado desde o Renascimento até o recente Movimento Moderno (EISENMAN, 1984). "Clássico", segundo o arquiteto, seria tudo aquilo que ainda segue os preceitos da Antiguidade Clássica. Mas como os tempos avançam, bem como os valores e as mensagens propagados pela arquitetura, manter uma forma que é aplicada desde o tempo da Grécia Antiga, ou mesmo seguir de modo similar a maneira de se conceber arquitetura quando as sociedades já são outras, seria, segundo Eisenman (1984), uma espécie de simulação (partindo do conceito de Jean Baudrillard): uma ficção da qual não é possível distinguir o real do irreal ou ilusório.

Partindo desta conclusão, de que a arquitetura produzida entre os séculos XV e XX não passou de uma ficção, Eisenman propõe uma arquitetura pela dissimulação, e não mais pela simulação. A distinção entre as duas condições, segundo Jean Baudrillard (1981, p. 9), está na concepção de que a primeira deixa "[...] intacto o princípio da realidade: a diferença continua a ser clara, está apenas disfarçada [...]", enquanto a segunda, não: essa fronteira encontra-se borrada, incerta. Para Eisenman (1984, p. 242), uma abordagem não seria oposta à outra, seriam apenas de naturezas diferentes. Por meio da dissimulação, Eisenman estaria, então, assumindo o caráter fantasioso de seus projetos, sua condição artificial.

Já as escavações, como Lambert (1994, p. 7, tradução nossa) bem caracteriza, " [...] traduzem essa investigação do objeto tridimensional isolado, abstrato para o vasto plano das topografias físicas e históricas de locais específicos." Elas operam por uma chave de leitura similar à realizada pela psicanálise. Pode-se dizer que Eisenman escava camadas abismais da cidade, recalques invisíveis superficialmente, da mesma maneira que psicanalistas exploram as profundezas do aparelho psíquico humano.

\section{"Psicanálise da cidade"}

Argumenta-se aqui que Eisenman trata a cidade e seus traços de modo semelhante ao descrito por Sigmund Freud (1925) em seu texto "Nota sobre o bloco mágico", no qual compara o dispositivo com o aparelho perceptivo humano. Isso porque o bloco mágico seria capaz de guardar "traços duradouros" (FREUD, 1925, p. 242) quando nele escritos, mas também possuiria a qualidade de descartar anotações em sua superfície quando já indesejadas, isto é, quando esse espaço passa a ser requisitado por novas anotações.

Resumidamente, tais propriedades devem-se por sua composição, já que é formado por uma tábua de cera sobreposta por duas películas que conformam uma folha fina e transparente: a superior é uma película de celuloide e a inferior é um papel encerado. Desta maneira, é possível escrever e apagar as anotações na película de celuloide sem que se perca seu registro, que fica como sulco na tábua de cera, acessível apenas quando retiradas ou elevadas as camadas superiores. Isso porque a película de celuloide 
funciona como um revestimento protetor para o papel encerado, o equivalente ao "protetor contra estímulos" (FREUD, 1925, p. 245) de um dos nossos sistemas psíquicos, aquele que acolhe as nossas percepções, "[...] podendo se comportar como uma folha em branco diante de cada nova percepção" (FREUD, 1925, p. 243), mas não as transforma em traços duradouros, aquilo que efetivamente fica armazenado em nossas mentes ao longo de nossas vidas.

Seguindo a analogia de Freud, tem-se a película de celuloide equivalente ao nosso protetor contra influxos externos possivelmente nocivos; o papel encerado funcionaria como o nosso sistema receptivo propriamente, responsável por acolher as percepções; e a tábua de cera seria como o nosso inconsciente, "[...] 'sistemas mnemônicos' por detrás dele [do sistema perceptivo]" (FREUD, 1925, p. 243), encarregada de armazenar os traços duradouros. Por mais que algumas lembranças possam ser "apagadas" de nosso sistema receptivo para que este consiga abrigar outras informações, elas ficam armazenadas em nosso inconsciente e muitas vezes só podem ser acessadas através de sessões de psicanálise (FREUD, 1924).

Afinal, se Freud (1924, p. 219-220) define a psicanálise como "[...] a teoria dos processos psíquicos mais profundos, não diretamente acessíveis à consciência, 'psicologia das profundezas' [...]", e se as "escavações" de Eisenman estariam indo para além do visível, cavando as "topografias históricas" (LAMBERT, 1994, p. 7, tradução nossa) para se chegar ao que "não é diretamente acessível à consciência", à superfície, não estaria ele, então, realizando um procedimento análogo à psicanálise, uma espécie de "psicanálise da cidade"?

E, se para se conseguir "ler" o que foi apagado na superfície do bloco mágico, é necessário dirigir-se à parte mais profunda do aparato, no caso, a tábua de cera; na mente humana o mesmo processo (de se chegar à profundidade, ao inconsciente) dá-se pela psicanálise; pode-se inferir, portanto, que os procedimentos que Peter Eisenman utiliza para escavar os arquivos profundos das cidades dá-se pelo mesmo procedimento. E o instrumento utilizado para acessar as camadas superficialmente inatingíveis da cidade (pois foram recalcadas, arquivadas numa espécie de inconsciente urbano) é o desenho.

Eisenman faz do desenho sua principal ferramenta porque é a partir dele que consegue operar com os elementos ausentes das cidades - existentes, no momento do projeto, apenas enquanto arquivos. K. Michael Hays (2010) defende que Eisenman, ao operar sobre o desenho, faz dele seu sítio em si, não a posição de seu "objeto" no espaço físico. Esses arquivos reproduzem a falta da forma; ela "[... não como um objeto de desejo arquitetônico [,] mas como um cenário para a disposição da ordem Simbólica [,] que também é do campo da ausência e da falta." (HAYS, 2010, p. 63, tradução nossa).

Partindo da leitura de Mal de arquivo, de Jacques Derrida (1995), pode-se interpretar que Eisenman parte das questões virtuais da cidade, do "arquivo do virtual" (DERRIDA, 1995, p. 86), uma vez que está lidando com o "atualmente ausente" (DERRIDA, 1995, p. 84) da cidade. Assim o arquiteto estaria operando com o que Derrida chama de "[...] arquivos inconscientes, mais geralmente, virtuais [...]" (DERRIDA, 1995, p. 84), material que, segundo Derrida, não é legível pelas normas da "história comum" (DERRIDA, 1995, p. 84), necessitando de outros recursos para sua leitura. 
O desenho não só permite a Eisenman acessar o "inconsciente urbano", como também "implantar" memórias que nunca existiram naquele espaço, naquela mente urbana, produzindo, assim, um novo arquivo. Pois, se Eisenman defende que o que foi produzido nas cidades já era uma ficção, sua atuação sobre elas também se dá pelo campo fictício. Com essa atitude, o arquiteto estaria levando ao máximo um princípio da memória que Paula Uglione e Cristiane Duarte resumem na seguinte declaração: "O que se produz no campo da memória, nos arquivos de memória, é sempre da ordem da ficção." (UGLIONE; DUARTE, 2011, p. 93). Em outras palavras, Peter Eisenman, nas "cidades de escavação artificial", estaria utilizando-se do caráter virtual do desenho, do arquivo, para conseguir realçar a condição de ficção da matéria das cidades. No projeto do Bloco 5 de Koch-/ Friedrichstraße, a abordagem de Eisenman não foi diferente.

\section{Bloco 5}

\section{Internationale Bauausstellung Berlin - IBA}

A escavação artificial de Peter Eisenman e Jaquelin Robertson em Berlim deu-se por ocasião da edição de 1984 da Exposição Internacional da Construção de Berlim (IBA, proveniente do seu nome em alemão, Internationale Bauausstellung Berlin), que objetivava repensar e reconstruir os centros históricos da capital ocidental da Alemanha (à época, bipartida), destruídos pela Segunda Guerra Mundial. O evento foi a oportunidade de pôr em prática as teorias da revisão e da crítica ao Movimento Moderno, como a sincronia do projeto de arquitetura com o projeto urbano, trazendo questões sobre tradição, história e memória de voltas às discussões sobre as cidades.

Segundo Josef Kleihues, diretor do setor Neubau da IBA, a proposta era de uma "reconstrução crítica da cidade", que se daria pelo "[...] confronto racional com os [seus] elementos constituintes" (KLEIHUES, 1991, p. 6, tradução nossa). Isto é, a inserção das novas construções em diálogo com a cidade existente em vez da posição de negação ao historicismo estipulada pelo modernismo (KLEIHUES, 1991, p. 7). Contudo, a "reconstrução crítica" está justamente no ato de repensar a cidade, de considerar suas pré-existências, mas sem que cada novo edifício perdesse sua singularidade e caísse em uma forma pastiche. Para Kleihues (1991), tal atitude garantiria individualidade a Berlim Ocidental, o que Laís Bronstein (2004, p. 6) caracterizou como "a pluralidade na totalidade".

Nesse contexto, vários arquitetos protagonistas da cena crítica arquitetônica foram convidados a participar dos concursos para as diferentes áreas a serem reelaboradas. Dentre eles, o escritório Eisenman/Robertson Architects, que veio a ser o vencedor da proposta para o Bloco 5 do conjunto habitacional social no bairro de Friedrichstadt, especificamente na região de Kochstraße e Friedrichstraße, próxima à interseção com o Muro de Berlim, componente fundamental para conceituar o projeto.

Na situação de reconstrução crítica da cidade, um dos questionamentos primordiais de Eisenman e Robertson (1983) foi com relação ao que eles acreditam ser uma crise da história: objeto de pilhagem dos modernos e de fetiche dos pós-modernos. Para os arquitetos, a história teria sido reduzida a uma espécie de nostalgia (EISENMAN; ROBERTSON, 1983), um desejo pelo passado, que, no caso de Berlim, teria sido interrompido pelas Guerras. 
O vazio da cidade - fruto de uma destruição que não se resume à física, causada pelos confrontos bélicos, mas que se estende à sua trajetória - manifesta-se também em interrupções na sua própria história. Na visão de Eisenman e Robertson, o vácuo entre uma ponta e outra da história interrompida seria preenchido, então, pela memória (EISENMAN; ROBERTSON, 1983). "Onde a história termina, a memória começa." (EISENMAN; ROBERTSON, 1983, p. 91, tradução nossa).

\section{Fuga da historicização do passado}

A partir da reflexão sobre a relação da cidade com sua história, Eisenman e Robertson realçam uma necessidade emergente da sociedade por uma ideia de passado, uma retomada da memória, o que Andreas Huyssen (2000, p. 14) caracteriza como uma "[...] comercialização em massa da nostalgia [...]", cujo boom data da década de 1970, com a moda retrô, a restauração historicizante de velhos centros urbanos, dentre outras atuações, que se intensificam na década de 1980 com os debates e a cobertura midiática sobre a Shoah.

O "implante de memórias" nas lacunas da história a que se referem Eisenman e Robertson (1983) pode ser relacionado ao consumismo desenfreado apontado por Huyssen (2000), que detecta a comercialização e o lucro sobre a história e a memória. Memórias de massa, chamadas pelo autor de "memórias imaginadas" (HUYSSEN, 2000, p. 18), muito mais fáceis de esquecer do que memórias vividas. Conclui-se, desse modo, que a memória não só pode ser criada a partir de experiências, mas também imposta de uma maneira artificial, para vender um passado que nunca existiu. Isso é válido para uma cultura crescente da cópia, na qual reinam os remakes e o medo do esquecimento. Huyssen também destaca que tudo o que é lembrado é de natureza virtual, uma vez que "a memória é sempre transitória, notoriamente não confiável e passível de esquecimento [...]" (HUYSSEN, 2000, p. 37).

Segundo Nora (1984, p. 25), existe um apelo a tudo que se refere à memória, justamente por ela ter sido afastada dos hábitos sociais e, por isso, ela não se dar mais de maneira espontânea. A consequência desse processo que deixou de ser natural é o medo constante do esquecimento, a ânsia por preservar informações em um mundo paradoxal saturado de informações. "Fala-se tanto sobre memória porque não há mais memória." (NORA, 1984, p. 19, tradução nossa).

Em seu projeto para a habitação social de Berlim, Peter Eisenman e Jaquelin Robertson exploram de maneira crítica esse caráter de artificialidade da memória, que pode ser enquadrada como uma maneira de simulação imposta pela mídia. A atuação dos arquitetos está na aplicação exagerada e evidente do fictício, que, como anteriormente apresentado, dá-se pela dissimulação, o que será possível identificar pela maneira com que o conceito interfere no projeto para o Bloco 5. Mas, antes, faz-se necessária a exposição de algumas observações da dupla de arquitetos sobre o local para onde seu projeto é planejado.

\section{Memória de Friedrichstadt}

Para Eisenman e Robertson (1983), a cidade de Berlim é o locus do vácuo histórico, devido ao fato de mostrar-se como marco de continuidade e, ao mesmo tempo, fim do lluminismo - cuja racionalidade e esclarecimento levaram à duas Grandes Guerras. 
E o local designado para o projeto é o locus da memória: a proximidade do sítio do projeto com o Muro apenas ressalta a configuração de cidade-museu que ele confere a Berlim ao circundá-la (EISENMAN; ROBERTSON, 1983), além de guardar o registro de grandes transformações que por lá passaram, como os muros delimitadores de suas fronteiras em outras épocas.

Mas essa memória é considerada pelos arquitetos como dotada de uma natureza ambivalente: "[...] a memória de algo que uma vez existiu e prosperou, mas também, em sua condição peculiar, o embalsamamento de algo vivente no presente." (EISENMAN; ROBERTSON, 1983, p. 92, tradução nossa). Tal memória carregaria a condição de simultaneidade de inclusão e exclusão, de lembrar e de esquecer (EISENMAN; ROBERTSON, 1983, p. 92), pois, ao mesmo tempo que foi palco de um passado glorioso, exaltado e que deveria ser lembrado, sua situação atual é de degradação, assolação - consequências desse mesmo triunfo, o que levou a cidade à vergonha. Por mais que se tente recalcar o fato da devastação, a lembrança, ele fica arquivado, "[...] pois um recalque arquiva também aquilo cujo arquivo ele dissimula ou encripta." (DERRIDA, 1995, p. 86). "No consciente ato de esquecer, não se pode evitar de lembrar." (EISENMAN; ROBERTSON, 1983, p. 92, tradução nossa).

\section{Anti-memória de Friedrichstadt}

Para que Eisenman e Robertson consigam abordar no projeto para o Bloco 5 a dualidade que identificam na memória de Berlim, eles recorrem ao dualismo também presente em sua história: de um lado, as peculiaridades da história local, suas singularidades, o que antes faziam da cidade algum lugar(EISENMAN; ROBERTSON, 1983); de outro, a cidade que se tornou vaga, do mundo, "[...] sua especificidade e identidade [que] foram sacrificadas no altar da história moderna [...]" (EISENMAN; ROBERTSON, 1983, p. 92), o que a fez cair na encruzilhada de todos os lugares e nenhum lugar (EISENMAN; ROBERTSON, 1983, p. 92), sucumbiu ao Estilo Internacional e ao que não é particular de lugar nenhum, ao genérico.

Na intenção de, ao mesmo tempo, "[...] memorizar um lugar e negar a eficiência dessa memória" (EISENMAN; ROBERTSON, 1983, p. 92, tradução nossa), Einseman e Robertson conceituam, assim, o que chamam de anti-memória.

Com o conceito de anti-memória, os arquitetos pretendem afastar-se do uso de uma ideia sentimental ou nostálgica, que acreditam ser próprios da memória (EISENMAN; ROBERTSON, 1983). Para eles, a anti-memória evita a procura por um acontecimento passado - o que não quer dizer que esteja ligada ao esquecimento, apenas não tem a intenção de restaurar algo que já não está mais presente, algo passado (EISENMAN; ROBERTSON, 1983).

A anti-memória, então, opera sobre o vazio: não possui alusões históricas, nem "[...] clama por um futuro mais perfeito ou uma nova ordem" (EISENMAN; ROBERTSON, 1983, p. 92, tradução nossa). Ela é uma maneira de obscurecer a realidade do passado, aquilo "[...] que de fato torna a realidade do presente nenhum lugar." (EISENMAN; ROBERTSON, 1983, p. 92, tradução nossa); em oposição à memória, que, pela nostalgia "[...] obscurece a realidade do presente [...]" (EISENMAN; ROBERTSON, 1983, p. 92, tradução nossa) - nega a presença do Muro à procura da restauração do passado. 
Neste projeto, Eisenman e Robertson trabalham tanto com a memória quanto com a anti-memória justamente pela oposição que ambas estabelecem entre si, e assim conseguem produzir um "[...] objeto suspenso, um fragmento congelado sem passado e sem futuro, um lugar. Digamos que é de seu próprio tempo." (EISENMAN; ROBERTSON, 1983, p. 92, tradução nossa). Uma arquitetura suspensa no tempo, que, a partir da união de ambos os conceitos, é a criação de um objeto que se relaciona com o passado, mas não busca por ele: é própria de seu tempo, de modo a reconhecer sua condição atual, a produção de um lugar.

Para Francisco Lucena (2010), o objeto suspenso ao qual se referem Eisenman e Robertson é o reflexo do processo de escavação artificial, da sobreposição das diversas camadas históricas da cidade por meio do desenho. Mais uma vez, ele, o desenho, é o responsável por escavar a memória e a anti-memória. E esse processo dá-se, mais precisamente, pelo uso do grid. O desenho é o que dá acesso ao virtual, ao arquivado, mas é o grid aquele que permite a plena manipulação dos elementos para a construção da narrativa, da ficção.

\section{Grid}

O grid é uma malha imaginária utilizada por Peter Eisenman e Jaquelin Robertson para articular todo o projeto para o Bloco 5. Mas, além disso, ele é a ferramenta mais importante de todo o processo de escavação e sobreposição das camadas históricas e mnemônicas da cidade. Hays (2010, p. 72) argumenta que o grid, neste projeto, é elevado à posição de grande significante arquitetônico, pois é simultaneamente o diagrama de estruturas hipotéticas do lugar, o material de suporte para as funções do edifício e uma estrutura reiterativa e autorreflexiva (a reafirmação de que falavam Eisenman e Robertson sobre o projeto ser o "objeto de seu próprio tempo").

E as camadas históricas e mnemônicas incorporadas nesses diversos grids que se sobrepõem (bem como as próprias história e memória na cidade) são derivadas dos elementos de grande significado para Berlim, aliadas das estruturas hipotéticas das quais fala Hays. Essas sim seriam os "implantes" de memória, sendo uma delas a grande protagonista desse processo de escavação: a projeção de Mercator. Sua importância relaciona-se à segunda natureza de história que os arquitetos identificam em Berlim, aquela que registra uma cidade do mundo, abdicada de seus aspectos singulares e identitários.

A malha de Mercator é "[...] um padrão genérico universal sem história, lugar ou especificidade" (EISENMAN; ROBERTSON, 1983, p. 92, tradução nossa), elaborada pelo geógrafo flamenco Gerardus Mercator em 1569 durante o período das Grandes Navegações. Foi a primeira a abordar todo o globo terrestre e a aplicar a projeção cilíndrica (depois de provada a esfericidade da Terra pela circunavegação de Fernão de Magalhães, em 1522). Com esse "[...] sistema de marcação mais neutro e artificial [...]" possível, que desempenha o papel de "amarrar Berlim ao mundo" (EISENMAN; ROBERTSON, 1983, p. 92, tradução nossa), os arquitetos articulam as camadas provenientes da singularidade de Berlim. Através desse processo, eles aliam tanto a condição real quanto a condição artificial da cidade.

O elemento artificial, como já dito, é a malha de Mercator. Já aqueles que condicionam particularidade à cidade, componentes de sua história, estão sob forte influência do Muro de Berlim: são os antigos muros que fundaram e delimitavam a cidade em épocas anteriores, especificamente dos séculos XVIII e XIX. No caso do muro mais antigo, ele 
Figura 1: croquis conceituais da concepção do Bloco 5 para a unidade habitacional de Koch-/Friedrichstraße, indicando a projeção de Mercator (visível na figura pela malha vermelha mais espaçada, que atinge a altura do Muro de Berlim) sobre as malhas da cidade, estabelecendo o que se pode ler nas inscrições da imagem " [...] um segundo conjunto de paredes" (tradução nossa), "novos edifício crescem da interseção do grid de Mercator" (tradução nossa). Tais malhas embasam o projeto e retornam como as configurações das fachadas. Peter Eisenman, 1981-1985. Fonte: $<$ https://eisenmanarchitects.com/ IBA-Social-Housing-1985>. apresenta-se apenas como traço, ausente da superfície urbana. No muro mais recente, que ainda possui uma parte presente na cidade, no entanto, não é utilizado por Eisenman e Robertson em sua formação original, mas sim por meio de uma reconstituição artificial, "[...] uma racionalização hipotética do que teria sido." (EISENMAN; ROBERTSON, 1983, p. 92, tradução nossa). Isto é, mesmo quando estão operando com memórias "oficiais" de elementos históricos de Berlim, os arquitetos enxertam uma carga de ficção, constroem uma nova memória a partir da anti-memória (pois é o grid de Mercator o principal elemento da anti-memória e o articulador dessas operações imaginárias).

A grande operação de Eisenman e Robertson está na extração e sobreposição de grids por meio da extensão da forma desses elementos provenientes das memórias da cidade (sejam elas "verdadeiras" ou não) e da sua condição presente. Ou seja, o projeto é concebido a partir da superposição de malhas oriundas do muro ausente da cidade de Berlim do século XVIII, da reconstrução fictícia do muro fundador (ainda presente, mas "adulterado") da capital alemã do século XIX, do atual tecido urbano da cidade e do próprio Muro de Berlim em si - o maior símbolo da situação física e social de Berlim do momento, pois carrega a "[...] monument[alidade] da erosão da unidade da cidade e do mundo, [que] forma um nexus dos muros em diferentes níveis que se tornam um compósito do datum da memória." (EISENMAN; ROBERTSON, 1983, p. 92, tradução nossa). E, acima de todos estes substratos mnemônicos, os arquitetos posicionam a projeção de Mercator, "extrudada" até atingir a altura do Muro (3,30m).

Eisenman e Robertson realizam, portanto, uma espécie de cartografia da memória da cidade (figuras 1 e 2). Porém, ela é subjugada e apagada pela presença do muro artificial implantado (a projeção de Mercator tridimensionalizada). Ela (a junção quase ilegível de malhas) passa segmentar uma cidade já dividida, deixando uma cicatriz permanente em sua superfície (EISENMAN; ROBERTSON, 1983). A sobreposição da anti-memória à memória.

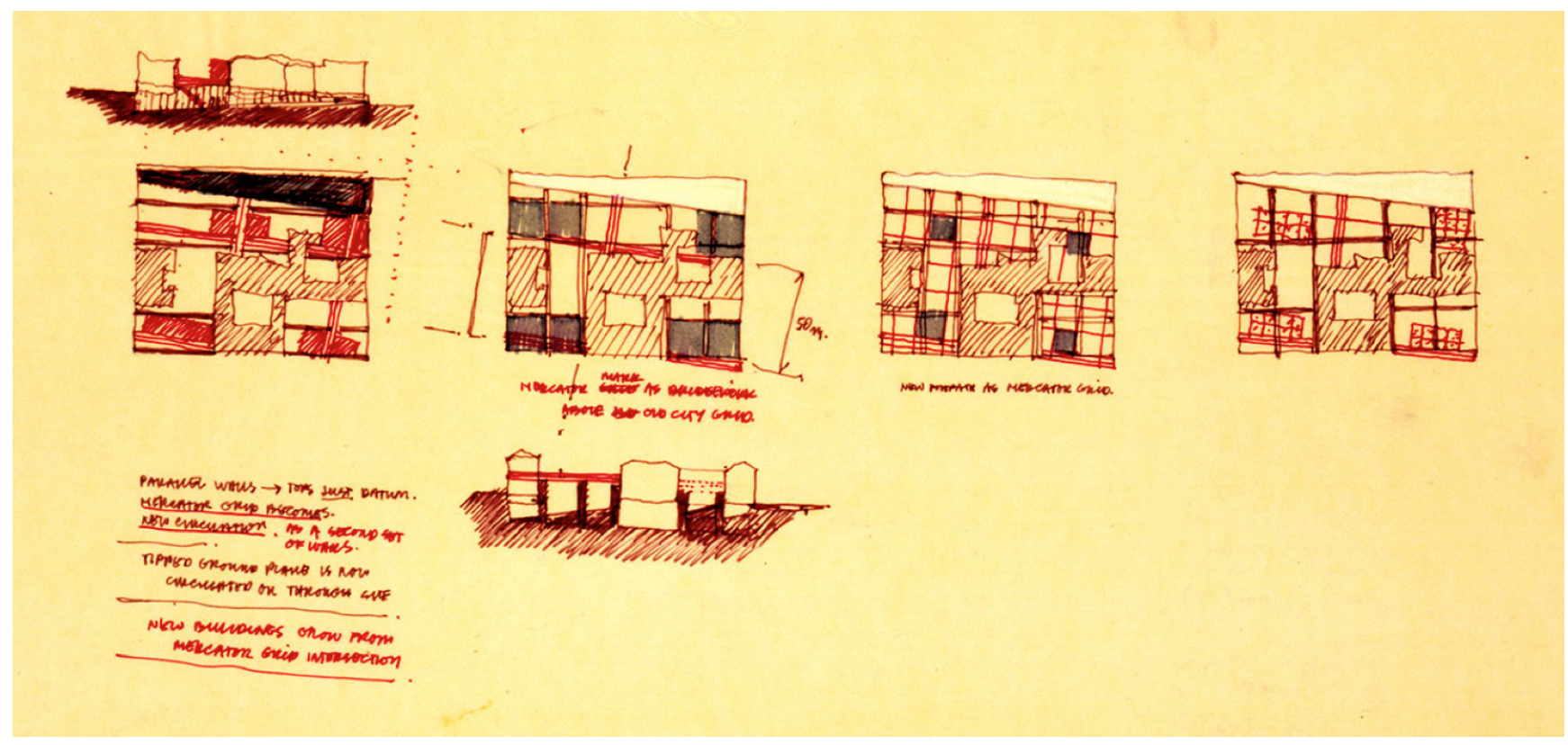


Figura 2: Desenho da sobreposição de malhas em planta baixa. Peter Eisenman e Jaquelin Robertson, 1981-1985. Fonte: $<$ https://eisenmanarchitects.com/ IBA-Social-Housing-1985>

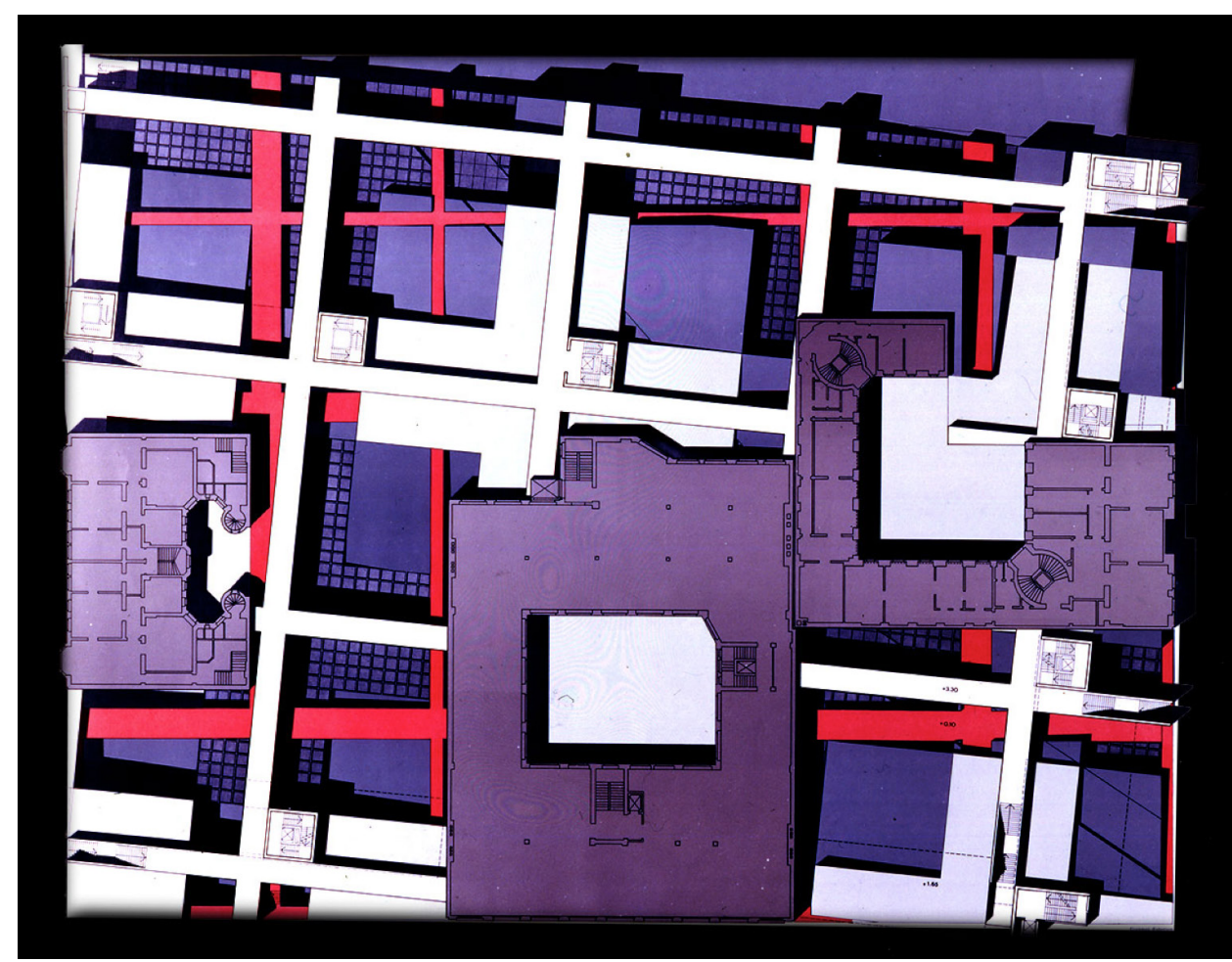

Mesmo que não em sua completude, este projeto foi efetivamente executado, o que não foi o caso de outras "escavações artificiais" de destaque, como a de Veneza (1978), fruto de uma conferência que visava gerar uma discussão sobre novas alternativas para os centros históricos degradados, mas que ficou apenas no plano investigativo, virtual; e a de Paris (1987), cuja intenção era a formulação do paisagismo para o Parc La Villette, em parceria com Jacques Derrida, mas cujo plano original não foi concretizado.

Resumidamente, a forma que o edifício adquiriria é o resultado da tridimensionalização da malha de Mercator, por onde se poderia caminhar num jardim elevado ao nível do terraço (figura 3). Contudo, essa parte do edifício não foi executada, apenas os blocos de apartamentos. As memórias "cicatrizadas", que foram recuperadas do inconsciente da cidade para depois serem subjugadas à artificialidade da malha "neutra" (EISENMAN; ROBERTSON, 1983, p. 92, tradução nossa) de Mercator, são expostas nas fachadas (figuras 4 e 5), trazendo à superfície do edifício a lembrança contida naquele locus histórico. Segundo Eisenman e Robertson (1983), a relação de perpendicularidade entre a planta baixa (sobreposta à "cartografia mnemônica") e as fachadas (sobreposta pela mesma junção de malhas) gera um reflexo entre elas (mesmas), "[...] cria[ando] um vácuo de anti-memória e um espaço de memória" (EISENMAN; ROBERTSON, 1983, p. 93, tradução nossa). 
Figura 3: Terraço jardim cujos caminhos são conformados pela tridimensionalização das malhas utilizadas para a concepção do projeto. Essa parte do edifício não foi executada. Peter Eisenman e Jaquelin Robertson, 1981-1985. Fonte: <https:// eisenmanarchitects.com/IBA-Social-Housing-1985>.

Figura 4: Exposição na fachada das malhas que orientam 0 projeto, vista da rua Kochstraße no ponto de transferência para a Rudi-Dutschke-Straße. Peter Eisenman e Jaquelin Robertson, 1981-1985. Fonte: <https:// eisenmanarchitects.com/IBA-Social-Housing-1985>.
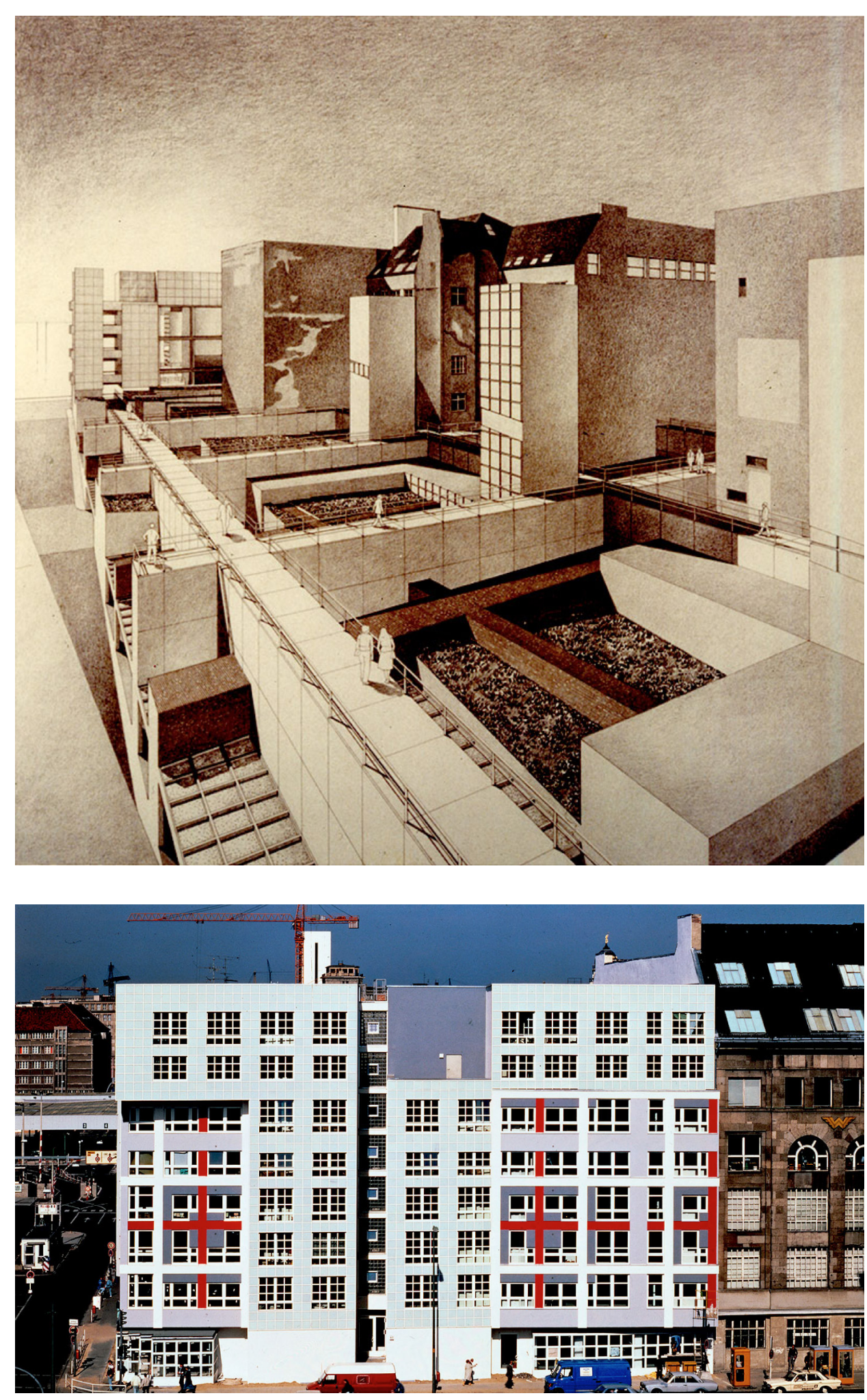
Figura 5: Detalhe da transposição das malhas na esquadria. Peter Eisenman e Jaquelin Robertson, 1981-1985. Fonte: <https:// eisenmanarchitects.com/IBA-Social-Housing-1985>.

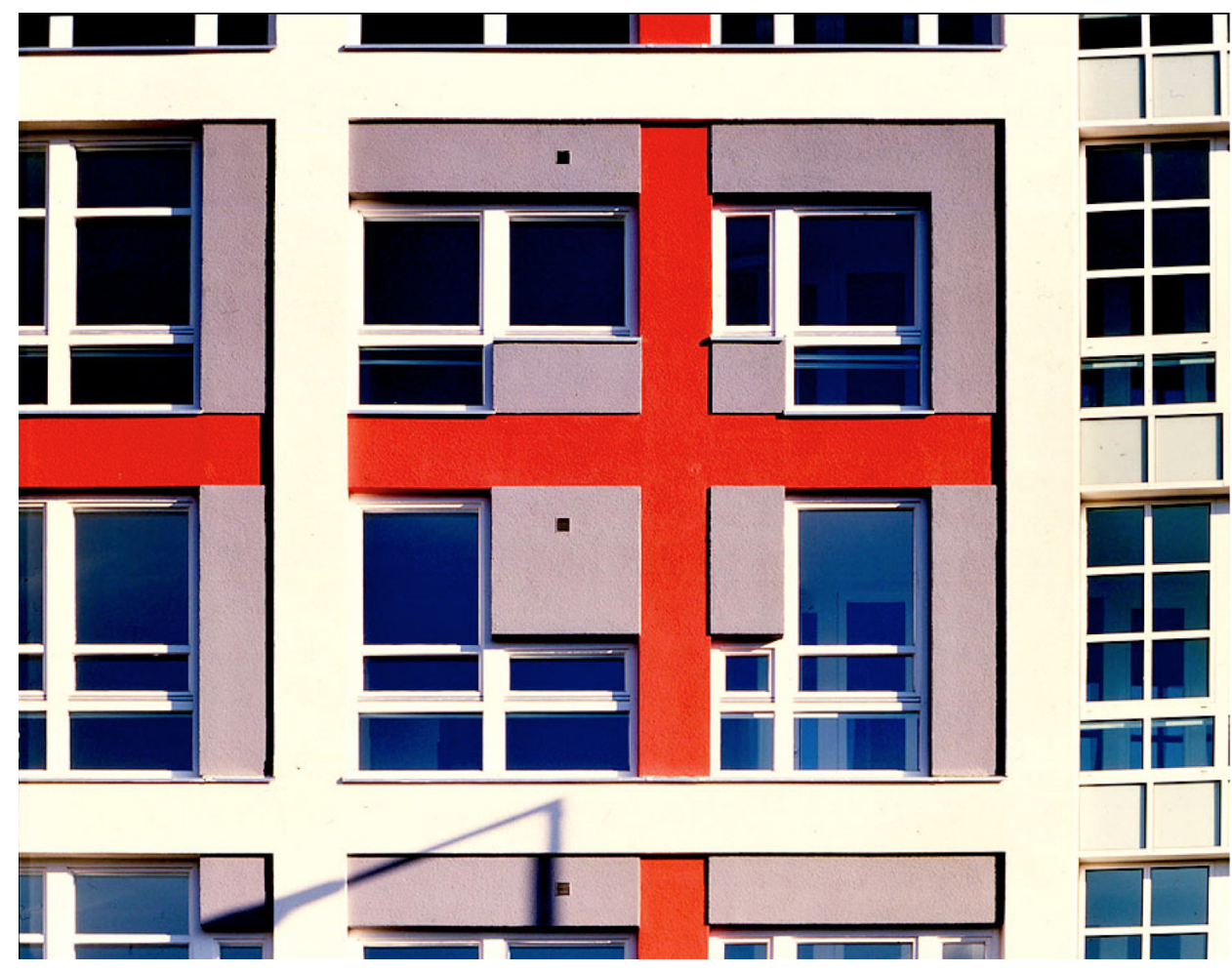

Dessa maneira, o ambiente gerado, principalmente o que seria o jardim, invoca a autorreflexão, "se torna o museu de sua própria arqueologia" (EISENMAN; ROBERTSON, 1983, p. 93, tradução nossa). Para os arquitetos, este é o resultado da natureza dúbia da memória e da anti-memória: os fragmentos que se tornam o todo (o resgate dos elementos singulares de Friedrichstadt, isto é, os fragmentos de seus muros recalcados e a posterior ação de reconstituí-los e estendê-los até formarem uma malha contínua) e o todo que se torna fragmentado (pela superposição do grid de Mercator e, com isso, supressão da expressividade da malha de muros).

Assim, o edifício não se direciona para o futuro nem busca por um passado: mantémse flutuante em seu próprio momento.

\section{Considerações finais}

Ao identificar que a memória, assim como a história, é algo que vai se sobrepondo ao longo do tempo, de modo que, metaforicamente, algumas ficam mais próximas à superfície do que outras, é comum considerar que aquelas que estão em uma camada mais inferior estão "esquecidas". Contudo, o desenvolvimento da psicanálise mostrou que as informações e lembranças que não são tão facilmente recuperáveis do subconsciente humano não necessariamente foram descartadas, podendo elas estar arquivadas no inconsciente, o que Sigmund Freud chamou de traços duradouros, muito mais difíceis de serem acessados justamente por se encontrarem em uma camada mais profunda da mente, aquela que também guarda os traumas. 
Com o aumento das discussões sobre o passado, principalmente por volta dos anos 1970 e 1980, influenciado não só pela retomada do interesse pela história em alguns campos do saber (como no exemplo da arquitetura), gerou-se também uma grande cobertura midiática acerca de questões da memória. Tal situação levou a uma comercialização desses estudos pelo passado, inclusive na "invenção" de algumas "lembranças", dando um caráter de artificialidade ao que se divulgava como memória.

Com o presente estudo, defendeu-se que a abordagem de Peter Eisenman e Jaquelin Robertson frente ao resgate da importância do passado não se deu de maneira usual. Ao invés de irem na contramão da artificialidade comercializada da história e da memória (uma atitude crítica possível), os arquitetos em questão fizeram de seus estudos e projetos um exagero desse caráter artificial. Contudo, Eisenman e Robertson fogem da nostalgia e apontam caminhos muito mais pessimistas do que o passado nostálgico veiculado (pela mídia, por exemplo). E, para isso, criaram o conceito de anti-memória, para afastarem de algo sentimental a sua ideia de passado.

A grande peculiaridade exposta neste artigo está no interesse de Eisenman e Robertson não pelo passado superficial, ou melhor, aquele que está visível desde a superfície da cidade, mas sim por aquele que se encontra ausente, recalcado, como traço duradouro das urbes. Conclui-se que, para acessarem a memória e a anti-memória das cidades que Eisenman e Robertson investigam, os arquitetos se fizeram valer de recursos da psicanálise - ferramenta essa que também é subvertida, pois não só traz à tona memórias urbanas recalcadas, como também as manipula de modo que saiam de seu estado "natural" para colocá-las no ápice de uma condição artificial e fictícia.

Pode-se dizer, portanto, que as "cidades de escavação artificial" de Eisenman são a máxima da crítica à superficialidade (tanto na acepção de camada pouco profunda quanto na extensão semântica de fútil carregada pelo verbete) da noção de passado idealizado e nostálgico que é comercializado pelos meios de consumo. Trata-se de uma crítica que não se apresenta apenas em papel, divulgado em revistas e livros, mas configura-se em projeto e, no caso do Bloco 5 de Koch-/Friedrichstraße, possui forma, é concreta. Uma crítica suspensa em seu tempo, que se mostra visível a todos que por lá passam, e que só foi possível através da escavação da memória e da antimemória por meio de um procedimento análogo à psicanálise.

\section{Agradecimentos}

Agradecemos à Coordenação de Aperfeiçoamento de Pessoal de Nível Superior (CAPES) pelo financiamento da pesquisa de mestrado.

\section{Referências bibliográficas}

BAUDRILLARD, Jean. A precessão do simulacro. In: Simulacros e simulação. Lisboa: Relógio d'Água, 1991. p. 7-57. 1981;

BRONSTEIN, Laís. The city of criticism to the modern movement. In: INTERNATIONAL PLANNING HISTORY SOCIETY, 11., 2004, Barcelona. Anais [...]. Barcelona: Universitat de Barcelona, 2004. p. 1-12;

DERRIDA, Jacques. Mal de Arquivo: uma impressão freudiana. Rio de Janeiro: Relume Dumará, 2001. 1995; 
EISENMAN, Peter; ROBERTSON, Jaquelin. Koch-/Friedrichstrasse, block 5. Architectural design, v. 53, n. 9, p. 91-93, London, jan. 1983;

EISENMAN, Peter. O fim do clássico: o fim do começo, o fim do fim [1984]. In: NESBITT, Kate (org.). Uma nova agenda para a arquitetura: antologia teórica (1965-1995). São Paulo: Cosac \& Naify, 2006. p. 233-252;

FOUCAULT, Michel. A arqueologia do saber. Rio de Janeiro: Forense Universitária, 2012. 1969;

FREUD, Sigmund. Resumo da psicanálise [1924]. In: Obras completas. v. 16. São Paulo: Cia das Letras, 2011, p. 200-226;

FREUD, Sigmund. Nota sobre o bloco mágico [1925]. In: Obras completas. v. 16. São Paulo: Cia das Letras, 2011, p. 241-246;

HAYS, K. Michael. Architecture's desire: reading the late avant-garde. Cambridge: MIT Press, 2010;

HUYSSEN, Andreas. Seduzidos pela memória: arquitetura, monumentos, mídia. Rio de Janeiro, Aeroplano, 2004. 2000;

KLEIHUES, Josep Paul. New building areas, buildings and projects. In: Internationale Bauausste/lung Berlin 1987 project report. English edition. Berlin: Felgentreff \& Goebel GmbH, 1991. p. 6-9;

LAMBERT, Phillys. Director's note. In: BÉDARD, Jean-François (Org.). Cities of artificial excavation. The work of Peter Eisenman, 1978-1988. Montréal: Canadian Center for Architecture and Rizzoli International Publications, 1994, p. 7-8;

LE GOFF, Jacques. História e memória. Campinas: Ed. UNICAMP, 1990. 1988;

LUCENA, Francisco. Peter Eisenman: autonomia crítica da arquitetura. 2010. Dissertação (Mestrado em História Social da Cultura) - Pontifícia Universidade Católica do Rio de Janeiro, Rio de Janeiro, 2010;

MONTANER, Josep Maria. Arquitetura e crítica. São Paulo: Gustavo Gili, 2015. 2007;

NORA, Pierre. Les lieux de mémoire. Montevideo: Ediciones Trilce, 2008. v. 1, t. 1, 2008. 1984;

POLLAK, Michael. Memória, esquecimento, silêncio. Estudos históricos, Rio de Janeiro, v. 2, n. 3, p. 3-15, 1989;

SCHWARTZ, Joan; COOK, Terry. Arquivo, Documentos e Poder: A construção da memória moderna. Registro - Revista do Arquivo Público Municipal de Indaiatuba. São Paulo: Fundação Pró-Memória de Indaiatuba, v. 3, n. 3, p. 15-30, jul. 2004;

SOLÀ-MORALES, Ignasi. Forma, memoria, acontecimiento. AV monografías, Madrid, v. 53, n. 2, p. 20-23, mayo/jun. 1995;

UGLIONE, Paula; DUARTE, Cristiane. Arquivos urbanos: memória e identidade na cidade. Quaderns de psicologia, Barcelona, v. 13, n. 1, p. 91-101, 2011. 